\title{
Simulation of the meandering flow path of a beaching slurry using a random walk technique
}

\author{
GI McPhail SLR Consulting Australia Pty Ltd, Australia
}

\begin{abstract}
Splitting a slurry stream through the operation of multiple discharges is an established method of improving the beaching profile both for conventionally thickened as well as high density thickened tailings. To maximise the beach slope, however, it is important to space the discharges sufficiently far apart to ensure that the split flow streams do not recombine down the beach. A random walk technique has been applied by the author to simulate the flow paths of multiple flow streams at a range of discharge spacings, and the results have been used to estimate the optimal number of discharges and spacings to maximise the slope of the deposited beach. This paper describes the theoretical basis for steepening the beach through simultaneous discharge of smaller flow streams, sets out a random walk analysis technique to assess the minimum spacing between the streams to maximise beach slope, and compares the results of the simulations with the full-scale operation at a number of tailings operations.
\end{abstract}

\section{Introduction}

The flow paths of tailings streams discharged onto a beach meander in a manner similar to silt laden rivers and river deltas. It is contended that the meander is caused by settling out of the solids along the flow path, which is continually changing the topography over which the stream flows. The flow regime is loose boundary and aggrading. In addition, the flow varies between laminar and turbulent at the bed face.

Dynamic simulation of the meander process has been carried out for river deltas (Seybold et al. 2007), but these are based on slurry consistencies of less than $5 \%$ solids by weight as compared with $30-75 \%$ solids in mineral tailings operations. The inclusion of non-Newtonian behaviour into these models is likely to be complex, given the difficulty of including this behaviour into pipe and channel flow where the boundaries are fixed and it is possible to carry out detailed measurements within and around the pipe.

Flows from simultaneous discharges will combine when the meanders intersect. Once combined, they will remain so beyond the confluence and will only re-separate if the changing meanders of the individual flows upstream of the confluence cause the flows to diverge. Observations suggest that the meander of a slurry depends on the flow rate, particle size distribution and rheology of the slurry. Variations in these parameters as a result of variations in mineralogy, ore processing and thickening are likely to be at the heart of the meanders.

Figure 1 shows meanders from single tailings discharges, i.e. where one discharge is operated at a time but the discharge point moves systematically along the crest of the tailings storage facility (TSF) at a spacing of $50 \mathrm{~m}$. It is evident from Figure 1 that over time the meanders vary over a beach width similar to the spacing of the discharges. Highlighted on Figure 1 is a typical meander. 


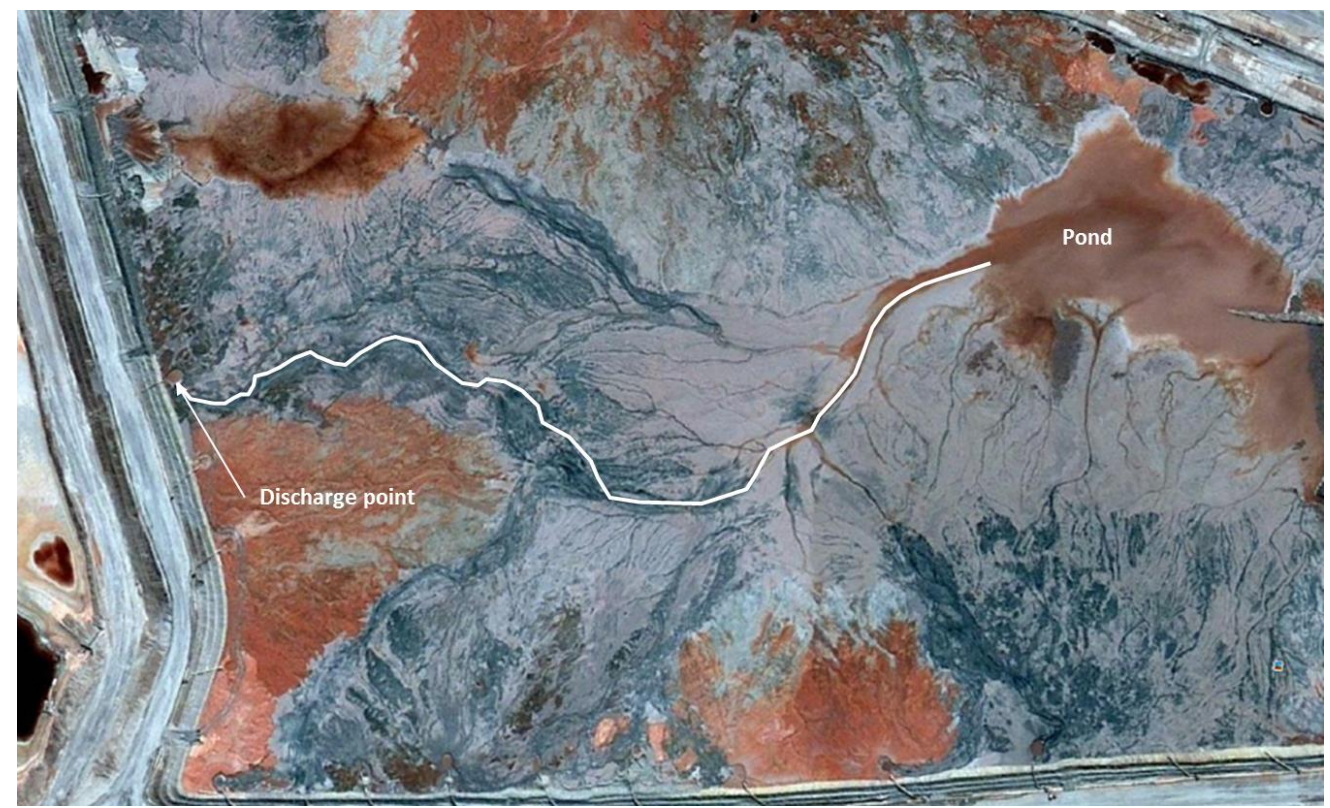

\section{Figure 1 Meandering flow from a sequence of single point discharges at $50 \mathrm{~m}$ spacing and a beach length of $365 \mathrm{~m}$}

At the opposite extreme, Figure 2 shows the meandering flows from 30 simultaneously operated discharges at $3 \mathrm{~m}$ centres while Figure 3 shows meandering from simultaneously operated discharges at $60 \mathrm{~m}$ centres.

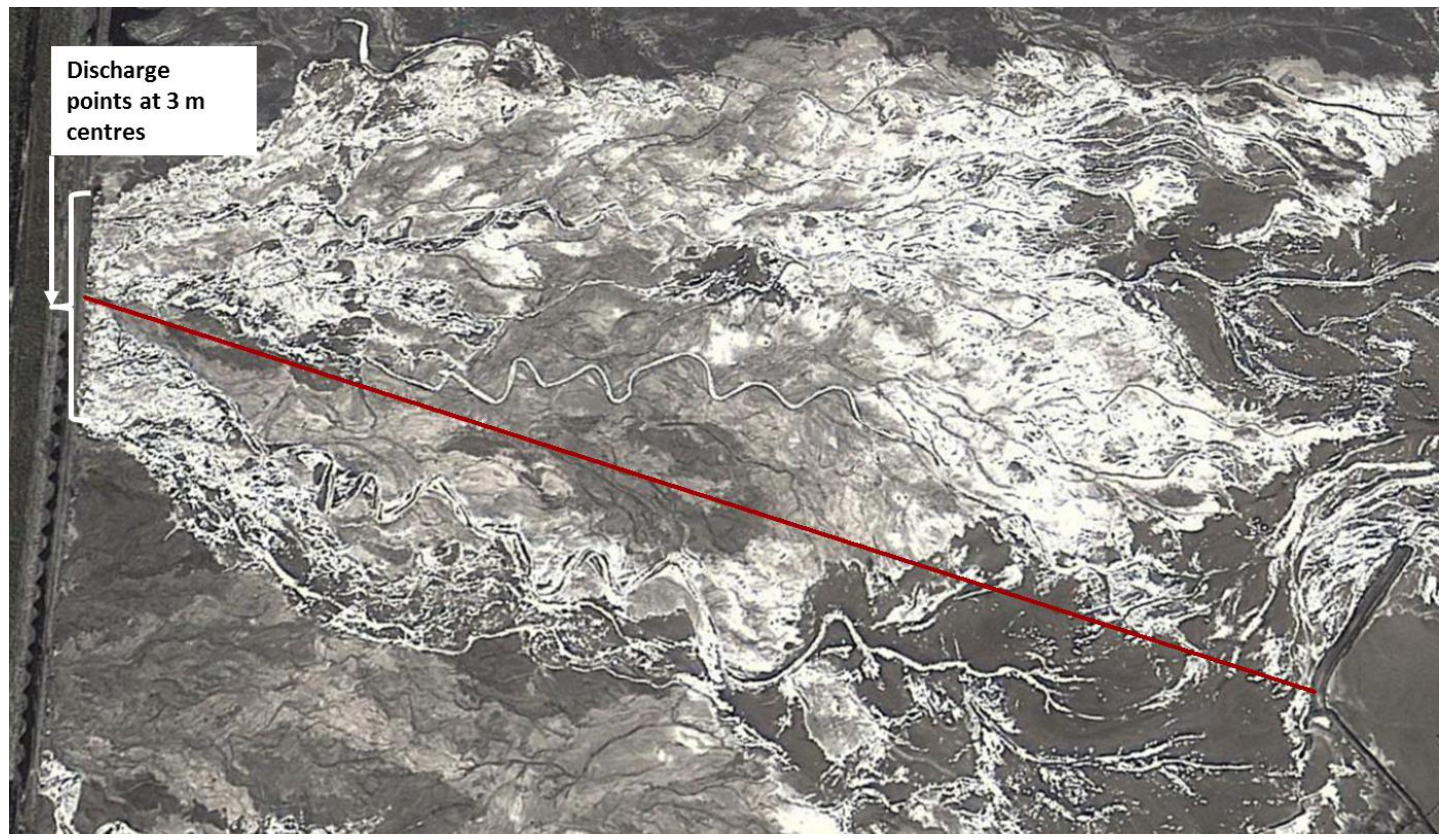

\section{Figure 2 Meandering flow from 30 simultaneously operated discharges at $3 \mathrm{~m}$ centres and a beach length of $740 \mathrm{~m}$}

In Figure 2, a number of points are evident:

- Due to the close spacing of the discharges, flows combine within $200 \mathrm{~m}$ of the discharge points and reduce to approximately four to six combined flows.

- The combined flow streams themselves meander over the distance between the combined discharges. 
- There are a number of well-defined and deep flow paths. These may be the result of flushing of the delivery pipeline at the end of the deposition cycle.

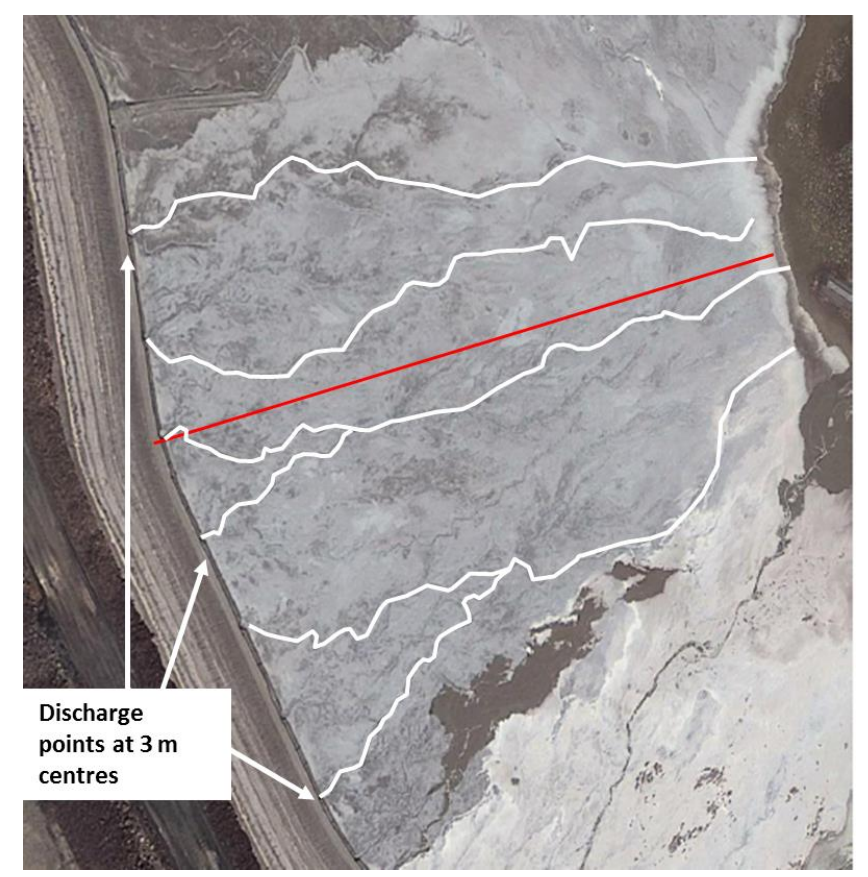

\section{Figure 3 Meandering flow from six simultaneously operated discharges at $60 \mathrm{~m}$ centres and a $\mathbf{4 0 0} \mathrm{m}$ beach length}

In Figure 3, a number of typical flow meanders have been highlighted in white. A close-up examination of the photo shows that flows have combined, split up and re-combined over the course of the deposition. It is evident that with the increased distance between discharges, the down-beach distance to combination of the flows is generally one to two times the spacing between the discharge points and number of flow channels reduces from six to between two to four.

Each photograph in Figure 1 through to Figure 3 represents a snapshot of the beach at a point in time. A sequence of snapshots would show that the meanders would change with time.

It was in the pursuance of a more readily accessible and immediate approach to the simulation of meanders that the author considered an approach that focuses on the stochastic/probabilistic methods of simulation rather than a pure hydrodynamic approach. The next section discusses the driver to simulate meanders, which are in accord with what is observed in the field.

\section{The need to simulate meanders}

The beach slope of a tailings stream is a function of the rheology, most specifically the shear stress, in the flow stream. The higher the shear stress the steeper the beach. In pipe hydraulics, flow $Q$ through a pipe of diameter $D$ and flow area $A$ will have a lower friction loss than a flow of $Q$ through two pipes of section area $=A / 2$, even though the velocities and total flows are the same. This is due to the fact that the wall length or perimeter of the single pipe is lower than the combined perimeter of the two pipes. The friction generates shear stress at the pipe perimeter in proportion to the total perimeter length, so the higher the perimeter length the higher the shear stress. The same situation applies to open channel flow. Two channels carrying flow $Q$ whose combined flow area is the same as a single channel carrying flow $Q$ will have a higher combined wetted perimeter than the single channel. More wetted perimeter, more friction, more shear stress, even though the velocities may be the same.

So, to steepen a beach, split the flow down into multiple simultaneous equal discharges. This principle has been known by tailings engineers and TSF operators for years and has formed the basis of many TSF designs. 
However, if the flows re-combine down the beach, the principle will operate in reverse; the beach will flatten as a result of the combination of flows. Moreover, since the flow resistance of the combined flow is lower, and nature always tends to a more optimum condition, the flows, once combined, are unlikely to separate unless a change occurs in the flow paths of individual flows upstream of the confluence that causes the flows to diverge. So, if a steeper beach is to be achieved it is vital to reduce the frequency with which flows combine over time.

In high density tailings deposition, where advantage is taken of the steeper beaching characteristics to stack the tailings so as to reduce the heights of confining embankments, ensuring that the beach profile meets the design requirements is vital. A steeper beach profile means less embankment volume, so it is highly desirable to go with multiple simultaneous discharges. But the distance between the discharges will be dictated by the TSF geometry and topography. For example, if the tailings throughput required 40 discharge points spaced at $50 \mathrm{~m}$ centres to handle the flow the discharge pipe (ring main), length would be $1,960 \mathrm{~m}$. It is common to provide two such lengths so as to accommodate pipe moves and maintenance without disrupting processing plant operation resulting in a required ring main length of $3,920 \mathrm{~m}$. In the event that the length of TSF embankment from which the tailings are to be discharged was insufficient to accommodate the ring main length of $3,920 \mathrm{~m}$, there would be a tendency to keep the number of spigots constant, since the intention is to steepen the beach, but move the spigots closer together, thereby shortening the ring main. However, moving the discharge points closer together increases the frequency over which the meandering flows may combine, thereby reducing the beach slope.

A method to assess the probability with which flow meanders may combine is therefore key to the design of the discharge system and indeed the design of the TSF.

\section{The random walk}

Focusing on a stochastic/probabilistic approach, the author considered a random walk engine for the simulation process. Consider a child playing on a tiled piazza where the rows of square tiles are represented by numbers and the columns by letters, as indicated in Figure 4 . Assume that the child made the following rules:

1. After landing on any square, the next square had to be on a diagonal from that square.

2. In deciding on the next square, a fair coin must be tossed to determine whether to go left on a diagonal or right on a diagonal to the next square.

If the child played the game repeatedly, always starting from the same initial block, $\mathrm{HO}$, and kept a running total of the number of times each square was landed on, the child would find that the probabilities of landing on the squares would be as indicated in Figure 4.

\begin{tabular}{|c|c|c|c|c|c|c|c|c|c|c|c|}
\hline & c & D & $E$ & $F$ & G & $\mathrm{H}$ & 1 & J & K & L & $M$ \\
\hline 0 & & & & & & 1 & & & & & \\
\hline 1 & & & & & $1 / 2$ & & $1 / 2$ & & & & \\
\hline 2 & & & & $1 / 4$ & & $1 / 2$ & & $1 / 4$ & & & \\
\hline 3 & & & $1 / 8$ & & $3 / 8$ & & $3 / 8$ & & $1 / 8$ & & \\
\hline 4 & & $1 / 16$ & & $1 / 4$ & & $3 / 8$ & & $1 / 4$ & & $1 / 16$ & \\
\hline 5 & $1 / 32$ & & $5 / 32$ & & $5 / 16$ & & $5 / 16$ & & $5 / 32$ & & $1 / 32$ \\
\hline
\end{tabular}

Figure 4 Probabilities of reaching squares 
The spread of probabilistic values across any row of squares is interesting. As would be expected, the probability that the child is in line with the starting point is higher than the probability of the child being either left or right of the starting point. Moreover, the probabilities are identical either side of column $\mathrm{H}$, i.e. they are symmetrically, and therefore normally, distributed along a row.

The probability of reaching any square in the game can be calculated using combinatorial notation as follows (Harr 1987):

$$
P[x, N]=N ! /\left(r !(N-r) !(1 / 2)^{N}\right.
$$

Where:

$\mathrm{N}=$ the row number.

$r=$ the entry number ( $r=0$ is always the first) in a valid square to either side of column $\mathrm{H}$.

$\mathrm{N}$ and $\mathrm{r}$ for the grid in Figure 4 are as indicated in Figure 5.

\begin{tabular}{|c|c|c|c|c|c|c|c|c|c|c|c|}
\hline & c & D & E & $\mathrm{F}$ & G & $\mathrm{H}$ & 1 & $J$ & $\mathrm{~K}$ & L & M \\
\hline 0 & & & & & & 1 & & & & & \\
\hline 1 & & & & & $\mathrm{~N}=1, \mathrm{r}=0$ & & $N=1, r=0$ & & & & \\
\hline 2 & & & & $N=2, r=0$ & & $\mathrm{~N}=2, \mathrm{r}=1$ & & $\mathrm{~N}=2, \mathrm{r}=0$ & & & \\
\hline 3 & & & $\mathrm{~N}=3, \mathrm{r}=0$ & & $N=3, r=1$ & & $N=3, r=1$ & & $N=3, r=0$ & & \\
\hline 4 & & $N=4, r=0$ & & $N=4, r=1$ & & $N=4, r=2$ & & $\mathrm{~N}=4, \mathrm{r}=1$ & & $N=4, r=0$ & \\
\hline 5 & $N=5, r=0$ & & $N=5, r=1$ & & $N=5, r=2$ & & $N=5, r=2$ & & $N=5, r=1$ & & $N=5, r=0$ \\
\hline
\end{tabular}

Figure 5 Combinatorial parameters for the grid in Figure 4

Now consider a tailings beach and imagine a grid across the beach. Assume that a random generator is at work and that the tailings stream moves from grid point to grid point down the beach on diagonals, i.e. it is always turning one side or the other - as per the random walk of the child over the piazza squares. This is in line with observations where the flows from a discharge are nearly always sinuous, i.e. seldom on a direct line from the discharge directly to the pond. Using Equation 1, it is feasible to calculate the probability of the flow meander being at a particular grid point. In addition, it is possible, using a spreadsheet, to set up a random generator on a grid and randomly generate entire flow paths. This information, in combination with the probabilities, provides a potentially useful way of assessing the probability of meanders coinciding, when deciding on an appropriate spacing for simultaneous discharges.

\section{$4 \quad$ Random walk simulation in a spreadsheet}

The author has set the aforementioned algorithm up in a spreadsheet. Figure 6 shows a typical output from the random walk algorithm for a square grid of $10 \mathrm{~m}$. Discharge points are placed at $20 \mathrm{~m}$ centres, i.e. every second grid point. The beach length has been set at 2,500 $\mathrm{m}$. 


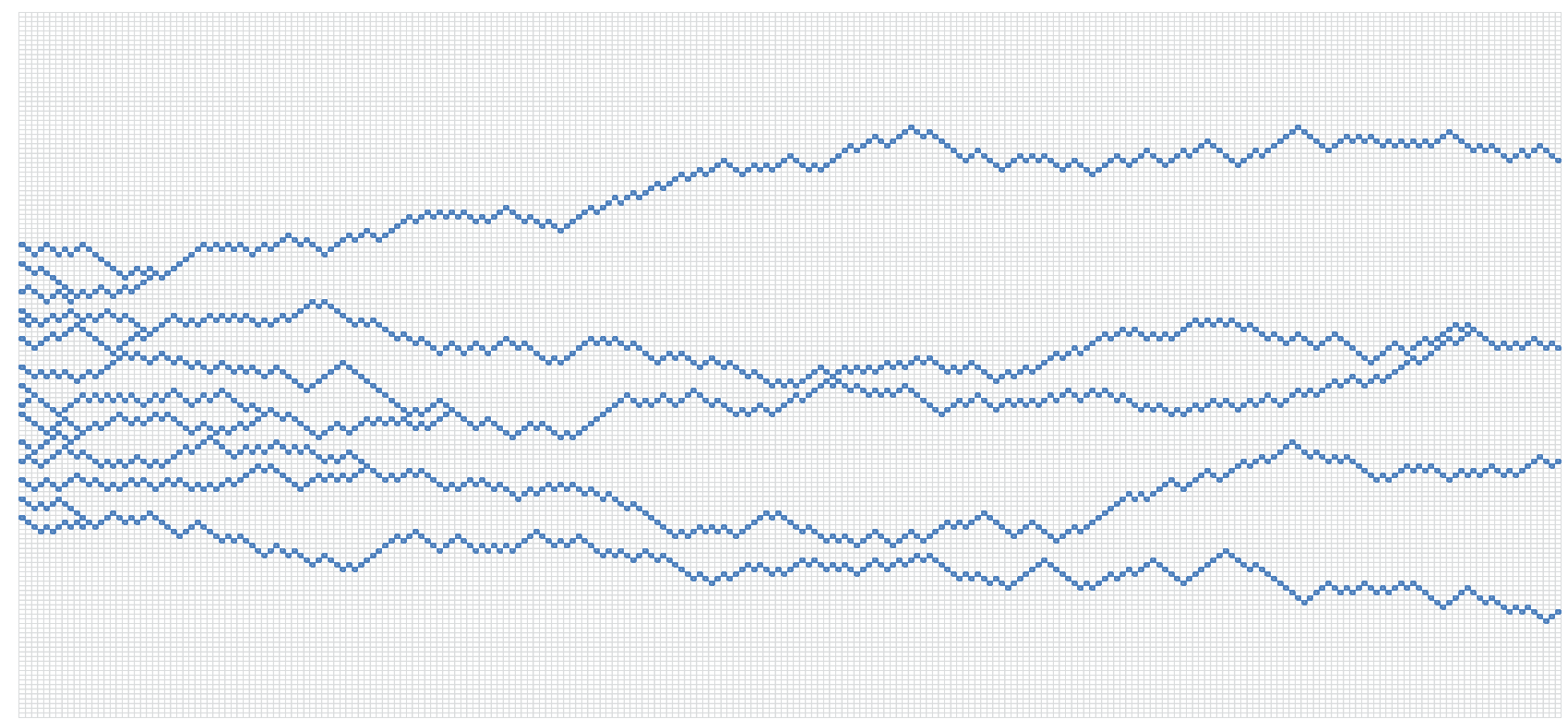

\section{Figure 6 Typical output from a random walk generation (flow is left to right)}

Figure 7 shows a close-up of the topmost three discharges in Figure 6 over the first $300 \mathrm{~m}$. The numbers in the squares indicate the number of original individual flows that have combined to generate one flow.

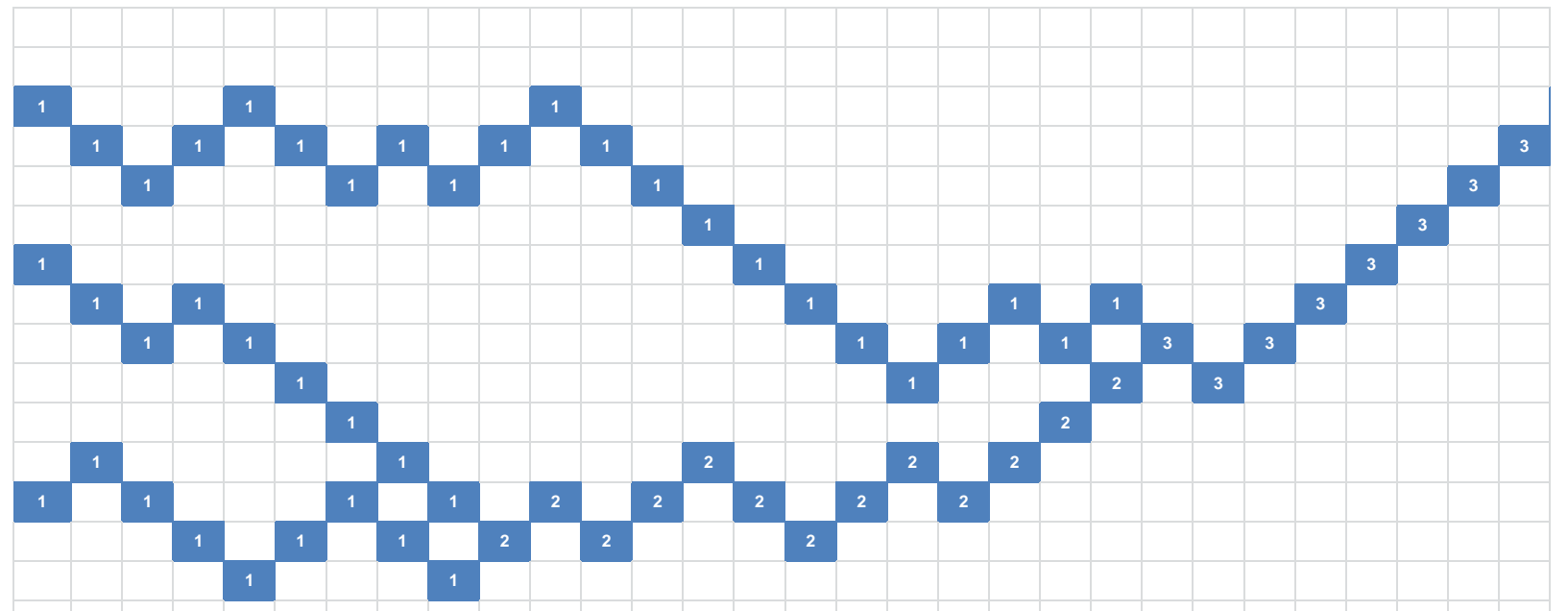

Figure 7 Close-up of the random walk paths over the first $100 \mathrm{~m}$ (flow is left to right)

The results indicated in Figures 6 and 7 represent snapshots of the beach just as the aerial photographs represent snapshots. If the simulations were to be repeated, the flow paths would change, as indicated in Figure 8. 

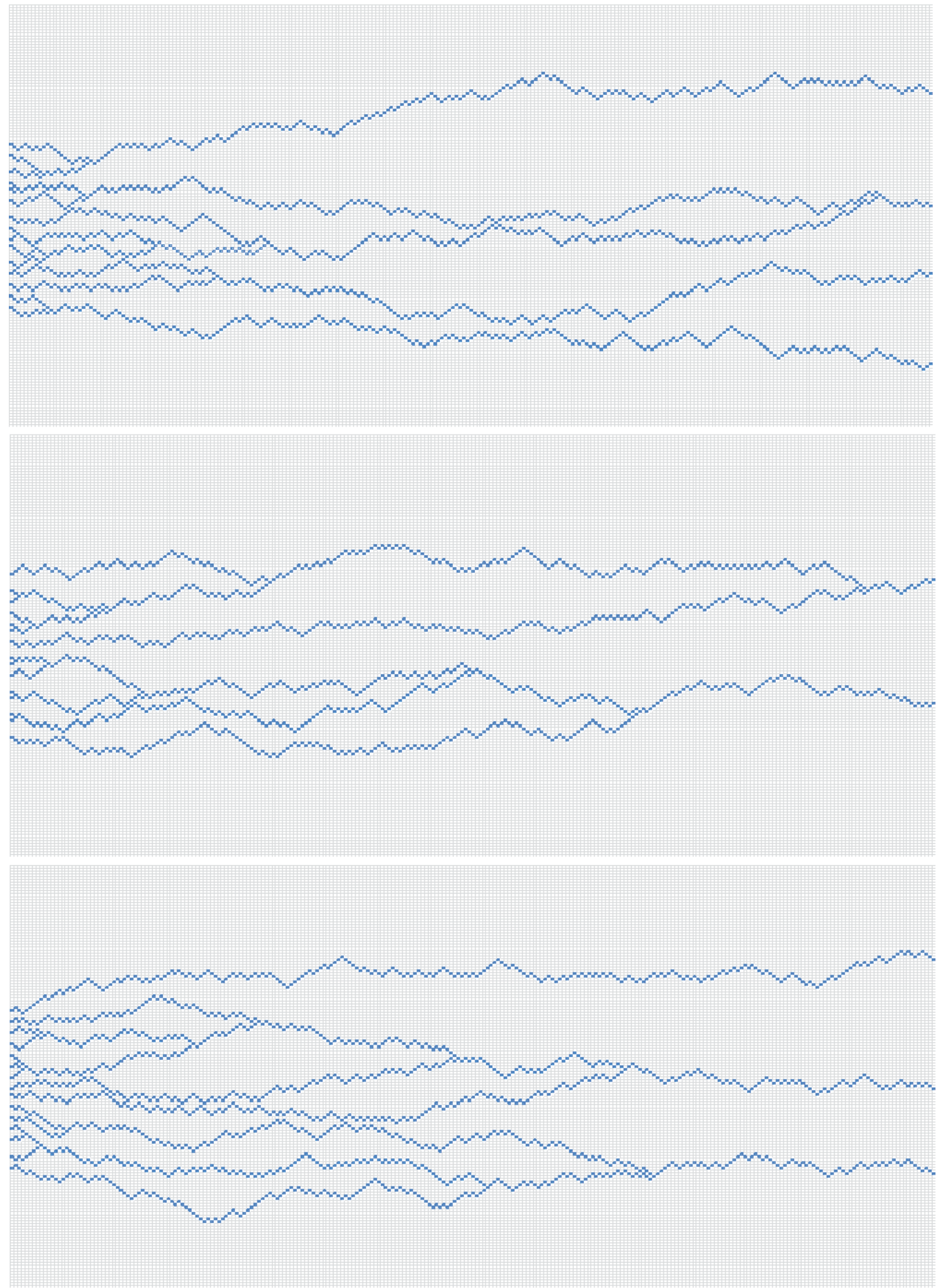

Figure 8 Results of three simulations for the discharges at $20 \mathrm{~m}$ centres over a $2,500 \mathrm{~m}$ beach (flow is left to right) 


\section{Comparison with actual beaches}

The discharge conditions in Figures 2 and 3 have been simulated using the spreadsheet simulation. The results are indicated in Figures 9 and 10.
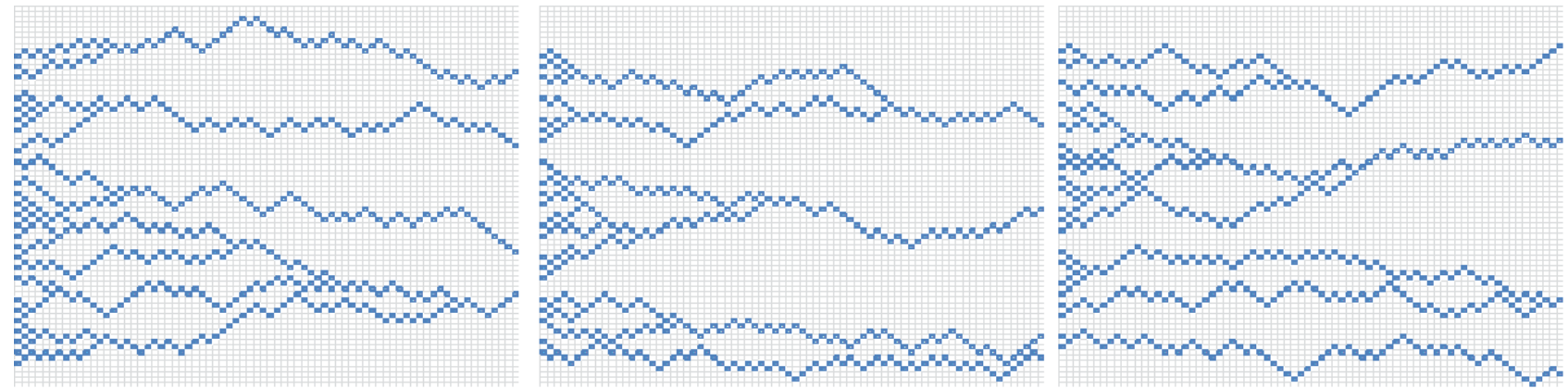

\section{Figure 9 Results of three simulations of 30 discharges spaced at $3 \mathrm{~m}$ centres over a $\mathbf{7 4 0}$ $m$ beach (flow is left to right)}

By comparing Figure 9 with Figure 2, it is evident that the reduction in flows from 30 down to four to six over a distance of less than $200 \mathrm{~m}$, as observed in Figure 2, has been simulated.
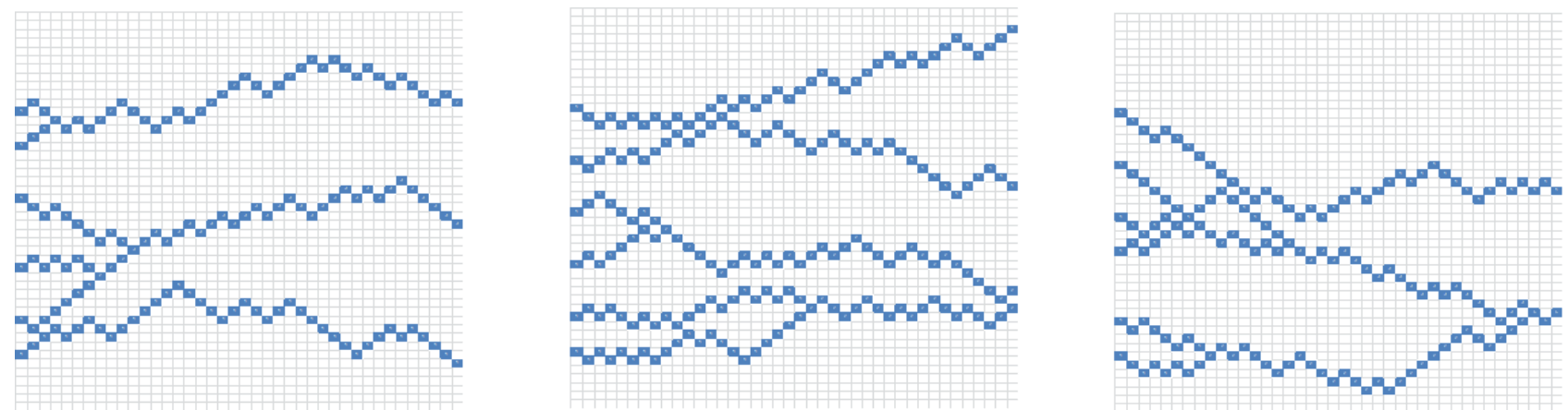

\section{Figure 10 Results of three simulations of $60 \mathrm{~m}$ centres and a $400 \mathrm{~m}$ beach (flow is left to right)}

Comparing Figure 10 with Figure 3 shows that the reduction in flows to three or four has been simulated and that the distance to combinations of flows is generally one to two times the distance between the discharges.

\section{The effective beach length}

Consideration of the aerial photographs as well as the simulated meanders shows that the effective beach length experienced by each flow stream is significantly longer than the direct distance from the discharge to the pond. On this basis, it would appear to be appropriate for beach calculations that require beach length as an input to use an effective beach length for the flow streams of $\sqrt{2}$ times the direct beach length.

\section{$7 \quad$ Conclusions}

Management of discharge rates through the use of multiple discharges has long been established by tailings engineers as being an effective way of steepening beach profiles. This applies to both conventionally thickened as well as high density thickened slurries.

It is contended that one of the principal drivers in the meandering process is slurry and flow variability dictated primarily by variations in mineralogy, processing issues as well as thickener operation. These tend to be stochastic in nature. 
The author has sought a probabilistic method of simulating beach meanders as a means to estimating an appropriate spacing between simultaneous discharges that would ensure that the probability and duration with which flow streams would combine can be minimised. Comparison of the random walk simulation results with typical beach observations suggests that the approach has merit.

\section{References}

Harr, ME 1987, Reliability-based Design in Civil Engineering, McGraw-Hill Book Company, New York.

Seybold, H, Andrade Jr, JS \& Herrmann, HJ 2007, 'Modelling river delta formation', Proceedings of the National Academy of Sciences, vol. 104, no. 43, pp. 16804-16809. 
